\title{
Association between Nutrition Label Reading and Nutrient Intake in Korean Adults: Korea National Health and Nutritional Examination Survey, 2007-2009 (KNHANES IV) University Hospital Healthcare System Gangnam Center; ${ }^{2}$ Department of Medicine, Seoul National University College of Medicine; ${ }^{3}$ Department of Family Medicine, Seoul National University Health Service Center, Seoul; ${ }^{4}$ Gunsan Health Center, Gunsan, Gunsan, Korea

Background: Nutrition labels provide various information on the nutrient contents of food. However, despite the recent increase in the interest in dietary intake and expansion of related policies, studies on the association between nutrition label reading and dietary intake are lacking in Korea.

Methods: This study analyzed the 2007-2009 KNHANES (Korean National Health and Nutrition Examination Survey) data. To examine macronutrients and micronutrients intake according to nutrition label reading, analysis of covariance was used. Multiple logistic regression analysis was also used to examine the association between adherence to dietary reference intake and nutrition label reading.

Results: Nutrition label reading was significantly high among women, youth, and those with high education and high household income. Nutrition label reading was associated with higher intake of calcium and vitamin $\mathrm{C}$ in men and the lower intake of calorie, carbohydrates and higher energy ratio of protein in women. Additionally, male nutrition label readers were associated with adherence to dietary reference intake of fiber (odds ratio [OR], 2.00; 95\% confidence interval [CI], 1.23 to 3.26 ) and calcium (OR, 1.26; $95 \% \mathrm{CI}, 1.03$ to 1.54). In women, there were no significant differences in the adherence to the dietary reference intake in fat, fiber, sodium, potassium, and calcium according to the nutrition label reading.

Conclusion: In men, nutrition label reading was associated with healthier intake of several micronutrients, although this was not observed in women. Consideration for clearly reporting vulnerable micronutrients in nutrition labels is necessary.

Keywords: Food Labeling; Food Habits; Recommended Dietary Allowances

Received: August 31,2013, Accepted: May 8, 2014

*Corresponding Author: Seung-Won Oh

Tel: +82-2-2112-5643, Fax: +82-2-2112-5794

E-mail:sw.oh@snu.ac.kr

Korean Journal of Family Medicine

Copyright (C) 2014 The Korean Academy of Family Medicine

(a) This is an open-access article distributed under the terms of the Creative Commons Attribution Non-Commercial License (http://creativecommons.org/licenses/by-nc/3.0) which permits unrestricted noncommercial use, distribution, and reproduction in any medium, provided the original work is properly cited.

\section{INTRODUCTION}

Nutrition labels provide the information on the main nutrients and their quantities in foods. In general, nutrition labels show the nutrient content of one serving of food and give a comparison with the daily recommended intake in a specific format. Nutrition labels have been made mandatory for almost all processed foods in the US and Canada for many years. ${ }^{1,2)}$ In Korea, nutrition labels show the contents of nine nutrients, 
including energy, carbohydrates, sugars, proteins, fats, saturated fats, trans fats, cholesterol, and sodium as per the regulations. ${ }^{1,3)}$

According to 'Nutrition labels and health claims: the global regulatory environment' published by World Health Organization (WHO) in 2004, the information on the nutrient content and their health promotion effect of processed foods are particularly important, and nutrition labels are useful tools to deliver this information. ${ }^{2)}$ Consumers read nutrition labels to compare different foods and to obtain information on negative characteristics of foods such as fat, calories, and sodium content. ${ }^{4,5)}$ Nutrition labels are becoming more important as useful tools that help users choose the appropriate foods for health management. The US Food and Drug Administration estimated in 1993 that the introduction of mandatory nutrition labeling would led to prevention of 39,200 cases of cardiovascular disease and cancer, and 12,902 cases of death for the next 20 years, leading to a national benefit of 4.4 to 22 billion dollars. ${ }^{6}$

Previous studies on factors that affect the use of nutrition labels have shown that females, and those of higher income and education level tend to read nutrition labels more frequently. ${ }^{7-9)}$ Similarly, analyses of data from the 2007-2008 Korea National Health and Nutrition Examination Survey (KNHANES) have shown that those with higher household income and education level were more likely to read nutrition labels. ${ }^{10)}$ A number of other studies have also looked into the association between the use of nutrition labels and the actual pattern of nutrient intake, some of which have shown that those who read nutrition labels tended to consume less calories and fats, and more fruits, vegetables and fiber. ${ }^{8,9,11-13)}$ On the other hand, a study by Harnack et al. ${ }^{14)}$ showed that there was no difference in the intake of calories between those who ordered from a fast food restaurant menu with the energy content displayed, and those who ordered from menus without. Elbel el al. ${ }^{15)}$ compared the difference in calories, saturated fat, sodium, and sugar content of foods ordered from fast food restaurants in selected areas of New York before and after the introduction of mandatory display of nutrition information on the menus. In a systematic review published in 2011, only 2 out of the 7 studies published between 2008 and 2011 showed an actual decrease in the intake of calories by displaying calories, and overall it was concluded that there was insufficient evidence that caloric intake was reduced. ${ }^{16)}$

Considering the fact that the main aim of nutrition labels is to promote healthy eating, it is important to compare the differences in diet habits due to nutrition label reading. Yet, there are limited studies in Korea that look into this effect in adults, except a few studies that were done on the use of nutrition labels and dietary habits in youth. ${ }^{17-20)}$ Therefore the aim of this study was to investigate the association between the use of nutrition labels and eating habits using the KNHANES data.

\section{METHODS}

\section{Subjects}

This study was based on data from the fourth KNHANES (2007-2009). KNHANES is a national project that was started in 1998 that targets all households and citizens living in the Republic of Korea to investigate the population's health status, health awareness and actions, and food and nutrition intake. The subjects were selected using a 3-step stratified cluster sampling method from the Population and Housing Census Report. A trained investigator visited each household to complete the questionnaires orally. In the fourth KNHANES, 24,871 out of 31,705 participated, resulting in a participation rate of $78.4 \%$. Of the 24,871 participants, we excluded 6,661 under the age of 20. We also excluded 2,183 people who did not respond to the question on the use of nutrition labels, and 2,103 people who did not respond to the question on sociodemographic factors that were found to be associated with the use of nutrition labels, resulting in a final study population of 13,924 people.

\section{Study Variables}

The sociodemographic factors associated with nutrition label reading used in this study were gender, age, body mass index (BMI), marital status (single, divorced or separated, married), education level (under middle school, middle school graduate, high school graduate, university graduate), household income, number of family members (1-2 persons, more than 3 persons), subjective perception of body figure (thin, average, obese), smoking status (non-smoker, ex-smoker, current smoker), and alcohol use frequency (less than once per month, twice per month to once weekly, twice weekly or more), as per previous studies. ${ }^{90)}$ The presence of chronic diseases such as hypertension, diabetes, and dyslipidemia were assessed using the response to 
the question on the presence of chronic disease.

The use of nutrition label was assessed using responses 'yes' or 'no' to the question 'Do you read nutrition labels when purchasing or choosing processed foods?' All those that did not respond to this question or answered 'I don't know' were excluded from analysis.

\section{Diet Assessment}

Evaluation of nutrition intake was performed using the daily nutrient intake data collected by 24-hour recall in KNHANES. Nutrients included in analyses were the calories, macronutrient (carbohydrates, proteins, fat) intake and energy ratio, fiber, sodium, potassium, vitamin A, carotene, retinol, and vitamin C. The recommended intake of nutrients was set by the nutrition guidelines published by WHO and the 2010 Dietary Reference Intakes for Koreans by Korean Nutrition Society. The recommended daily intake of sodium was under $2 \mathrm{~g}$, at least 3,500 $\mathrm{mg}$ for potassium, at least $700 \mathrm{mg}$ of calcium, and at least $20 \mathrm{~g}$ of fiber. The recommended intake of fat was under $25 \%$ and $30 \%$ of total energy intake.

\section{Statistical Analysis}

The subjects were divided into two groups depending on whether or not they read nutrition labels. The differences in variables including the age, gender, BMI, marital status, education level, household income, number of family members, subjective perception of body figure, smoking status, alcohol use, nutrition education, presence of hypertension, diabetes, or dyslipidemia were then analyzed using t-test and chi-square test. We confirmed that stratified gender analysis was possible using Mantel-Haenszel test for homogeneity and the subjects were subsequently analyzed for each gender. After correcting for variables that affect nutrition label reading, analysis of covariance was performed to compare the intake of individual nutrients between those who read nutrition labels and those who do not. Then multiple logistic regression analysis was performed to calculate and evaluate the odds ratio (OR) and 95\% confidence interval (CI) of the adherence to recommended daily intake of nutrients with nutrition label reading. In order to represent all Korean adults without biased estimates, sampling weights were applied to account for the complex sampling. Statistical analysis was done using Stata ver. 12.0 (Stata Co., College Station, TX, USA) and
P-values of 0.05 or less were taken to have statistical significance.

\section{RESULTS}

\section{General Characteristics of the Subjects}

The subjects were divided into two groups depending on whether or not they read nutrition labels, and the differences in these two groups were analyzed (Table 1). Of all 13,924 subjects, 3,185 (24.7\%) were nutrition label readers, of which 693 (12.2\%) were male and 2,492 (30.2\%) were female. The mean age of the nutrition label readers was 37.6 years, whereas that of non-readers was 46.3 years. The percentage of males of nutrition label users was $31.1 \%$ versus $56.4 \%$ in non-readers of nutrition labels. The education level and household income were both higher in the nutrition label readers. Those who had more than 3 persons in their family were more likely to read nutrition labels than those from smaller families of 1 to 2 members. Those who perceived themselves as being obese subjectively were also more likely to read nutrition labels. There were more non-smokers and a smaller percentage of people who drank alcohol 2 or more times each week in nutrition label readers. Those who had previously received nutrition education tended to read nutrition labels more, and there were more people with chronic diseases such as hypertension, diabetes and dyslipidemia in non-readers.

\section{Nutrient Intake and the Use of Nutrition Labels}

Multiple linear regression analysis was done to investigate the intake of nutrients depending on the use of nutrition labels (Table $2)$. In men, those who read nutrition labels had higher intake of calcium (534.8 mg vs. $576.1 \mathrm{mg}, \mathrm{P}=0.015)$ and vitamin C (106.3 $\mathrm{mg}$ vs. $117.2 \mathrm{mg}, \mathrm{P}=0.022$ ) compared to those who did not read nutrition labels. The calorie intake, carbohydrates, proteins, fat intake and energy ratio, fiber, sodium, potassium, vitamin $\mathrm{A}$, carotene, and retinol was not different between the two groups. In women, the calorie $(1,585.4 \mathrm{kcal}$ vs. $1,536.8 \mathrm{kcal}, \mathrm{P}=0.013)$ and carbohydrates (275.2 g vs. 267.1 g, P = 0.016) intake was lower in those who read nutrition labels, with higher intake of protein (13.9\% vs. $14.3 \%, \mathrm{P}<0.01$ ). There was no significant difference in the fat intake and energy ratio, fiber, sodium, potassium, calcium, vitamin $\mathrm{A}$, carotene, retinol, and vitamin $\mathrm{C}$ between users and non-users of nutrition labels. 
Table 1. General characteristics of study subjects $(n=13,924)$

\begin{tabular}{|c|c|c|c|}
\hline \multirow{2}{*}{ Characteristic } & \multicolumn{2}{|c|}{ Nutrition label reading } & \multirow{2}{*}{ P-value* } \\
\hline & No $(n=10,739)$ & Yes $(n=3,185)$ & \\
\hline Age (y) & $46.3 \pm 15.9$ & $37.6 \pm 10.6$ & $<0.01$ \\
\hline Sex (male) & $4,966(56.4)$ & $693(31.1)$ & $<0.01$ \\
\hline BMI $\left(\mathrm{kg} / \mathrm{m}^{2}\right)$ & $23.7 \pm 3.4$ & $23.3 \pm 3.3$ & $<0.01$ \\
\hline Marriage & & & $<0.01$ \\
\hline Unmarried & $1,068(17.3)$ & $546(24.7)$ & \\
\hline Single $^{\dagger}$ & $1,675(11.6)$ & $199(4.9)$ & \\
\hline Married & 7,996 (71.1) & $2,440(70.4)$ & \\
\hline Education (y) & & & $<0.01$ \\
\hline$<9$ & $3,680(22.7)$ & $158(4.0)$ & \\
\hline $9-12$ & $1,405(11.9)$ & $265(7.2)$ & \\
\hline $12-14$ & $3,408(39.1)$ & $1,422(45.8)$ & \\
\hline$\geq 14$ & $2,246(26.3)$ & $1,340(43.0)$ & \\
\hline Household income & & & $<0.01$ \\
\hline 1st quartile & $2,578(17.1)$ & $263(8.7)$ & \\
\hline 2nd quartile & $2,757(25.3)$ & $720(23.4)$ & \\
\hline 3rd quartile & $2,762(28.7)$ & $1,014(31.4)$ & \\
\hline 4th quartile & 2,642 (28.9) & 1,188 (36.5) & \\
\hline No. of family members & & & $<0.01$ \\
\hline $1-2$ & $3,920(26.6)$ & $533(15.9)$ & \\
\hline$\geq 3$ & $6,819(73.4)$ & $2,652(84.1)$ & \\
\hline Subjective perception of body shape & & & $<0.01$ \\
\hline Skinny & $1,957(17.6)$ & $353(12.0)$ & \\
\hline Normal & $4,461(40.8)$ & $1,258(39.3)$ & \\
\hline Obese & $4,321(41.6)$ & $1,574(48.7)$ & \\
\hline Smoking & & & $<0.01$ \\
\hline Non-smoker & $6,018(47.9)$ & $2,345(67.0)$ & \\
\hline Ex-smoker & $2,297(22.3)$ & $431(15.9)$ & \\
\hline Current smoker & $2,424(29.8)$ & $409(17.1)$ & \\
\hline Alcohol intake & & & $<0.01$ \\
\hline$\leq 1 / \mathrm{mo}$ & 6,161 (49.5) & $2,031(60.4)$ & \\
\hline 2/mo-1/wk & 2,127 (24.3) & 733 (24.6) & \\
\hline$\geq 2 / \mathrm{wk}$ & $2,451(26.2)$ & $421(15.0)$ & \\
\hline Nutrition education (yes) & 449 (3.9) & $282(8.8)$ & $<0.01$ \\
\hline Hypertension & $2,420(17.2)$ & 230 (6.3) & $<0.01$ \\
\hline Diabetes mellitus & $959(7.0)$ & $112(3.2)$ & $<0.01$ \\
\hline Dyslipidemia & $584(4.7)$ & $108(2.8)$ & $<0.01$ \\
\hline
\end{tabular}

Values are presented as weighted mean \pm standard error or numbers (weighted proportion).

*t-test for continuous variables; chi-square test for categorical variables. ${ }^{\dagger}$ Single: divorced + bereaved + separated. 
Table 2. Nutrient intake according to nutrition label reading

\begin{tabular}{|c|c|c|c|c|c|c|}
\hline \multirow{2}{*}{ Variable } & \multicolumn{2}{|c|}{ Male } & \multicolumn{3}{|c|}{ Female } & \multirow{2}{*}{ P-value* } \\
\hline & No $(\mathrm{n}=4,966)$ & Yes $(n=693)$ & & No $(n=5,773)$ & Yes $(\mathrm{n}=2,492)$ & \\
\hline Total energy (kcal) & $2,167.2(2,138.2-2,196.3)$ & $2,147.4(2,066.2-2,228.6)$ & 0.642 & $1,585.4(1,564.5-1,606.3)$ & 1,536.8 (1,505.0-1,568.5) & 0.013 \\
\hline Carbohydrate (g) & $338.2(334.2-342.3)$ & 335.7 (324.7-346.8) & 0.676 & $275.2(271.4-278.9)$ & 267.1 (261.3-272.9) & 0.016 \\
\hline Protein (g) & 77.7 (76.4-78.9) & $78.6(74.5-82.7)$ & 0.667 & $55.5(54.6-56.4)$ & $55.4(54.0-56.7)$ & 0.858 \\
\hline Fat (g) & $41.7(40.7-42.8)$ & $41.3(38.3-44.2)$ & 0.774 & $29.2(28.5-30.0)$ & $28.7(27.5-29.8)$ & 0.455 \\
\hline Carbohydrate $(\%)^{\dagger}$ & $67.7(67.3-68.0)$ & $67.5(66.6-68.4)$ & 0.691 & $70.2(69.8-70.5)$ & $69.8(69.3-70.3)$ & 0.276 \\
\hline Protein $(\%)^{\dagger}$ & $15.1(14.9-15.2)$ & $15.3(14.9-15.8)$ & 0.295 & $13.9(13.8-14.1)$ & $14.3(14.1-14.5)$ & $<0.01$ \\
\hline Fat $(\%)^{\dagger}$ & $17.2(17.0-17.5)$ & $17.2(16.6-17.8)$ & 0.859 & $15.9(15.6-16.1)$ & $15.9(15.5-16.3)$ & 0.976 \\
\hline Fiber (g) & $8.1(7.9-8.3)$ & $8.5(8.1-8.9)$ & 0.095 & $6.7(6.6-6.9)$ & $7.0(6.7-7.2)$ & 0.071 \\
\hline Sodium (mg) & $5,743.2(5,628.2-5,858.2)$ & $5,879.9(5,588.3-6,171.5)$ & 0.382 & $4,028.0(3,941.5-4,114.5)$ & $3,945.7(3,825.9-4,065.5)$ & 0.289 \\
\hline Potassium (mg) & $3,280.7(3,224.4-3,337.0)$ & $3,424.4(3,275.3-3,573.6)$ & 0.071 & $2,625.1(2,576.7-2,673.5)$ & $2,668.3(2,594.8-2,741.9)$ & 0.301 \\
\hline Calcium (mg) & $534.8(523.9-545.7)$ & $576.1(544.8-607.5)$ & 0.015 & $422.9(412.2-433.5)$ & $439.1(424.3-454.0)$ & 0.062 \\
\hline Vitamin A $(\mu \mathrm{g})$ & 839.4 (811.1-867.7) & 854.7 (777.9-931.5) & 0.712 & $691.3(665.2-717.3)$ & $720.2(672.6-767.7)$ & 0.231 \\
\hline Carotene $(\mu \mathrm{g})$ & 4,348.1 (4,196.7-4,499.6) & $4,390.5(3,978.0-4,803.0)$ & 0.849 & $3,605.7(3,461.2-3,750.1)$ & $3,824.7(3,549.3-4,100.2)$ & 0.092 \\
\hline Retinol $(\mu \mathrm{g})$ & $100.1(91.6-108.6)$ & $120.8(87.7-153.9)$ & 0.208 & $74.7(70.0-79.4)$ & $78.6(69.9-87.3)$ & 0.437 \\
\hline Vitamin C (mg) & $106.3(103.4-109.2)$ & $117.2(108.4-126.1)$ & 0.022 & $96.9(93.8-100.0)$ & $98.9(94.3-103.5)$ & 0.446 \\
\hline
\end{tabular}

Values are presented as weighted mean (95\% confidence interval). The means are adjusted with age, body mass index, marriage, education, income, family members, perception of body shape, nutrition education, smoking, alcohol, hypertension, diabetes mellitus, and dyslipidemia.

*From analysis of covariance models. ${ }^{\dagger}$ The percentage of energy.

Table 3. Associations between adherence to the dietary reference intake and nutrition label reading

\begin{tabular}{lcccc}
\hline \multicolumn{1}{c}{ Variable } & Unadjusted OR $(95 \% \mathrm{CI})$ & P-value* $^{*}$ & Adjusted OR ${ }^{\dagger}(95 \%$ CI $)$ & P-value* \\
\hline Male $(\mathrm{n}=5,659)$ & & & & \\
Fat $(<25 \%)^{\ddagger}$ & $0.68(0.55-0.84)$ & $<0.01$ & $0.96(0.77-1.21)$ & 0.740 \\
Fat $(<30 \%)^{\ddagger}$ & $0.86(0.63-1.16)$ & 0.312 & $1.22(0.89-1.68)$ & 0.212 \\
Fiber $(>20 \mathrm{~g})$ & $2.01(1.29-3.13)$ & $<0.01$ & $2.00(1.23-3.26)$ & 0.01 \\
Sodium $(<2,000 \mathrm{mg})$ & $0.73(0.46-1.16)$ & 0.181 & $0.89(0.55-1.42)$ & 0.061 \\
Potassium $(>3,500 \mathrm{mg})$ & $1.33(1.10-1.59)$ & $<0.01$ & $1.20(0.99-1.45)$ & 0.026 \\
Calcium $(>700 \mathrm{mg})$ & $1.35(1.12-1.63)$ & $<0.01$ & $1.26(1.03-1.54)$ & 0.867 \\
Female $(\mathrm{n}=8,265)$ & & & $0.99(0.83-1.17)$ & 0.594 \\
Fat $(<25 \%)^{\ddagger}$ & $0.63(0.54-0.74)$ & $<0.01$ & $0.94(0.75-1.18)$ & 0.976 \\
Fat $(<30 \%)^{\ddagger}$ & $0.62(0.50-0.76)$ & $<0.01$ & $1.01(0.64-1.58)$ & 0.102 \\
Fiber $(>20 \mathrm{~g})$ & $1.05(0.70-1.58)$ & 0.800 & $1.15(0.97-1.37)$ & 0.187 \\
Sodium $(<2,000 \mathrm{mg})$ & $0.83(0.72-0.97)$ & 0.018 & $1.10(0.95-1.27)$ & $1.10(0.92-1.30)$ \\
Potassium $(>3,500 \mathrm{mg})$ & $1.24(1.09-1.42)$ & $<0.01$ & $<0.01$ & 0.299 \\
Calcium $(>700 \mathrm{mg})$ & $1.23(1.06-1.43)$ & & & \\
\hline
\end{tabular}

OR: odds ratio, CI: confidence interval.

*By multiple logistic regression analysis. ${ }^{\dagger}$ Adjusted for age, body mass index, marriage, education, income, family members, perception of body shape, nutrition education, smoking, alcohol, hypertension, diabetes mellitus, and dyslipidemia. ${ }^{\ddagger}$ The percentage of energy. 


\section{Association between the Use of Nutrition Labels and the Adherence to Recommended Intake of Major Nutrients}

To investigate the association between the use of nutrition labels and the adherence to recommended intake of major nutrients such as fat, fiber, sodium, potassium, and calcium, we conducted multiple logistic regression analysis (Table $3)$. In men, nutrition label readers were found to follow the recommended fiber intake of $20 \mathrm{~g}$ or more (OR, 2.00; 95\% CI, 1.23 to 3.26) and recommended calcium intake of $700 \mathrm{mg}$ or more (OR, 1.26; 95\% CI, 1.03 to 1.54), with no difference in the adherence to recommended intake of fat, sodium, and potassium. However in women, there was no difference in the adherence to recommended intake of fats, fiber, sodium, potassium, and calcium depending on the use of nutrition labels.

\section{DISCUSSION}

In this study, nutrition label users were found to be relatively younger, have higher proportion of females, higher level of education and income, and higher number of family members compared to non-users of nutrition labels. In men, nutrition label users had higher intake of calcium and vitamin $\mathrm{C}$ compared to non-users. In women, the total intake of calories and carbohydrates was lower in nutrition label users, with higher energy ratio of protein, although there was no difference in the intake of other micronutrients. In men, nutrition label readers were more likely to adhere to the recommended intake of fiber and calcium, but not fat, sodium and potassium, whereas in women, the use of nutrition labels did not affect the adherence to the recommended intake of any nutrients.

Similar to previous findings, this study also showed that younger people and women were more likely to read nutrition labels. ${ }^{9,10)}$ This seems to be due to having different opportunities to receive nutrition education or information on nutrition labels according to gender and age group. The different preferences of processed foods, which have nutrition labels, may also have affected the results. Women tend to show higher interest in dietary habits than men, and the gender differences may also be reflecting the role of married women who generally look after the diet of the family. Similar to previous findings, we also found that those with higher level of education and income were more likely to read nutrition labels. This is likely to be due to these people having higher interest in health, maintaining a healthy diet, and thus showing more interest in nutrition labels when choosing foods. We also found that those who subjectively perceived themselves as being obese were more likely to read nutrition labels, which is likely to be due to their increased interest in calories and nutrition intake.

Previous studies on the association between the nutrition label use and the intake of nutrients have shown different results according to study subjects and method. A study done in university students in the US showed that those who read nutrition labels had higher intake of fruits, vegetables, and fiber. ${ }^{13)}$ A study which analyzed data from Continuing Survey of Food Intakes by Individuals and Diet and Health Knowledge Survey of the US showed that the use of nutrition labels was associated with higher vitamin $\mathrm{C}$ intake and lower cholesterol intake. ${ }^{21)} \mathrm{On}$ the other hand, a study that compared nutrition intake before and after displaying the nutrients on fast food menus in New York showed that although subjects answered that their choice from the menu was affected by nutrition labels, their actual intake of calories, saturated fats, sodium, and sugar was not different. ${ }^{15)} \mathrm{A}$ systemic review of previous studies on the effect of displaying caloric content and the intake of calories reported that only 2 of the 7 studies published between 2008 and 2011 showed an actual decrease in calories by caloric content display. ${ }^{16)}$ This difference may be due to different study designs and populations, as some studies were done in adolescent populations and there were differences in cities, income level, and fast food restaurants.

It is likely that nutrition label readers would have higher interest in healthy diets compared to non-readers. However, there was no difference in the intake of antioxidants such as vitamin A, retinol, and carotene as well as sodium intake between readers and non-readers of nutrition labels in both genders. It is well known that high sodium intake is associated with increased risks of chronic disease such as hypertension, stroke, and cardiovascular disease, ${ }^{22)}$ and WHO recommends a daily intake of more than $2.5 \mathrm{~g}$ of potassium and under $2 \mathrm{~g}$ of sodium. The same recommended amount of sodium is used in Korea, although according to the 2011 KNHANES, the average sodium intake of Koreans is more than double of this, at $4.9 \mathrm{~g}$ per day. The adverse effect of sodium was well recognized, and other countries 
have made efforts to reduce salt intake at a national level. For example, a national campaign to reduce the sodium intake in UK led to a successful reduction in sodium intake by $10 \%$. Similar successful sodium reduction has been achieved in Japan, Finland, and Ireland. ${ }^{23,24)}$ There have been recent movements in Korea to reduce sodium intake, but there are still limitations such as the diet tradition of salted foods and eating soups with meals, and increased consumption of processed foods. Sodium intake is also different in men and women. According to 2010 KNHANES, the percentage of sodium intake relative to the recommended daily intake of $2 \mathrm{~g}$ per day was $403 \%$ in men and $289 \%$ in women, showing that men were consuming much more sodium than women. In this study, men also showed higher sodium consumption, but there was no difference in sodium intake and the adherence to recommended intake of sodium according to nutrition label use in both genders.

Our study showed that in men, nutrition label users had higher calcium intake and were more likely to adhere to the recommended intake, although this was not observed in women. Calcium deficiency affects bone metabolism and thus increases the risk of osteoporosis and fractures in women. ${ }^{25,26)}$ There have also been reports of calcium deficiency and its association with diabetes $^{27)}$ and colorectal disease. ${ }^{28)}$ Calcium intake is important in the aging population, but it is also one of the most deficient nutrients in Koreans for all ages and genders. The recommended calcium intake in the US is 1,000 to $1,200 \mathrm{mg}$, whereas the recommended intake is 650 to $750 \mathrm{mg}$ in Korean adults. However, according to the 2010 KNHANES, the average calcium intake was $529 \mathrm{mg}$, with the percentage of recommended intake of $79 \%$ in men and $69 \%$ in women, showing that women had relatively lower calcium intake than men.

In this study, only $24.7 \%$ of the subjects responded that they read nutrition labels. If the rate of nutrition label use was higher, the intake of other micronutrients may have been significantly different between nutrition label readers and nonreaders. Nevertheless, the fact that the use of nutrition labels (where the majority of nutrition label users were young with high socioeconomic status) was not associated with the intake of important nutrients for Koreans shows that the current nutrition labeling policy does not have a significant effect on the vulnerable nutrients. However, we should note that only processed foods have nutrition labels. The majority of foods do not have nutrition labels, which means that even though a person chooses foods based on nutrition labels it would only have a small effect on the overall nutrient intake. However, if the nutrition labeling policy is changed so that the important nutrients such as sodium and calcium are emphasized and their effect on health is displayed, it may lead to changes in the overall pattern of food intake. ${ }^{1)}$

There are several limitations of this study. Firstly, this is a cross-sectional study which means that it cannot explain the causal relationship between the use of nutrition labels and the actual nutrient intake. The use of nutrition labels may affect diet patterns, but on the other hand, those who have more interest in health and have healthier dietary habits may be more likely to read nutrition labels. A number of studies done overseas have shown that the display of nutrition information on restaurant menus have effects on the selection and consumption of foods by consumers, ${ }^{11,15)}$ although this has not been studied in depth in Korea. Secondly, the 24-hour recall that we used to evaluate the consumption of nutrients is limited in that it cannot reflect long-term dietary habits. ${ }^{29)}$ This can be addressed by using a food frequency questionnaire, which will need to be developed and adjusted to fit the purpose of the study. Thirdly, the use of nutrition labeling was determined by self-response questionnaires, and hence may be prone to recall bias.

However this study is important in that it has used data that represents the adult population in Korea to confirm the association between the use of nutrition labels and actual nutrient intake, in a setting of limited domestic studies on the use of nutrition labels. The results of this study will need to be confirmed with further studies on the effects of nutrition labeling on nutrient intake.

\section{CONFLICT OF INTEREST}

No potential conflict of interest relevant to this article was reported.

\section{ACKNOWLEDGMENTS}

This study was supported by grant no. 34-2013-0310 from SK Telecom Research Fund. 


\section{REFERENCES}

1. Kang H, Shin EJ, Kim HN, Eom KY, Kwon KI, Kim SY, et al. Food nutrition labeling (processing food, food service business) in Korea. Korean J Food Sci Ind 2011;44:21-7.

2. Hawkes C. Nutrition labels and health claims: the global regulatory environment: World Health Organization report. Geneva: World Health Organization; 2004.

3. Ministry of Food and Drug Safety. Nutrition label guide [Internet]. Cheongwon: Ministery of Food and Drug Safety [cited 2013 Mar 15]. Available from: http://www.mfds. go.kr/nutrition.

4. Weimer J. Accelerating the trend toward healthy eating. In: Weimer J. America's eating habits: changes and consequences. Agriculture Information Bulletin: no. 750. Washington (DC): U.S. Department of Agriculture, Economic Research Service, Food and Rural Economics Division; 1999. p. 385.

5. Cowburn G, Stockley L. Consumer understanding and use of nutrition labelling: a systematic review. Public Health Nutr 2005;8:21-8.

6. Zarkin GA, Dean N, Mauskopf JA, Williams R. Potential health benefits of nutrition label changes. Am J Public Health $1993 ; 83: 717-24$.

7. Besler HT, Buyuktuncer Z, Uyar MF. Consumer understanding and use of food and nutrition labeling in Turkey. J Nutr Educ Behav 2012;44:584-91.

8. Satia JA, Galanko JA, Neuhouser ML. Food nutrition label use is associated with demographic, behavioral, and psychosocial factors and dietary intake among African Americans in North Carolina. J Am Diet Assoc 2005; 105:392-402.

9. Neuhouser ML, Kristal AR, Patterson RE. Use of food nutrition labels is associated with lower fat intake. J Am Diet Assoc 1999;99:45-53.

10. Kang HT, Shim JY, Lee YJ, Linton JA, Park BJ, Lee HR. Reading nutrition labels is associated with a lower risk of metabolic syndrome in Korean adults: the 2007-2008 Korean NHANES. Nutr Metab Cardiovasc Dis 2013;23:876-82.

11. Roberto CA, Larsen PD, Agnew H, Baik J, Brownell KD. Evaluating the impact of menu labeling on food choices and intake. Am J Public Health 2010;100:312-8.

12. Tandon PS, Wright J, Zhou C, Rogers CB, Christakis DA. Nutrition menu labeling may lead to lower-calorie restaurant meal choices for children. Pediatrics 2010;125:244-8.

13. Graham DJ, Laska MN. Nutrition label use partially mediates the relationship between attitude toward healthy eating and overall dietary quality among college students. J Acad Nutr Diet 2012;112:414-8.

14. Harnack LJ, French SA, Oakes JM, Story MT, Jeffery RW, Rydell SA. Effects of calorie labeling and value size pricing on fast food meal choices: results from an experimental trial. Int J Behav Nutr Phys Act 2008;5:63.

15. Elbel B, Kersh R, Brescoll VL, Dixon LB. Calorie labeling and food choices: a first look at the effects on low-income people in New York City. Health Aff (Millwood) 2009;28:w111021.

16. Swartz JJ, Braxton D, Viera AJ. Calorie menu labeling on quick-service restaurant menus: an updated systematic review of the literature. Int J Behav Nutr Phys Act 2011;8:135.

17. Cho SH, Yu HH. Nutrition knowledge, dietary attitudes, dietary habits and awareness of food-nutrition labelling by girl's high school students. Korean J Community Nutr 2007; 12:519-33.

18. Hyon SM, Kim JW. Improvement of dietary attitudes of elementary students by nutrition labeling Education. Korean J Community Nutr 2007;12:168-77.

19. Chang SO, Lee O, Lee KS. Intake of processed foods and the effects of nutrition label education in 5th grade children. J Korean Diet Assoc 2008; 14:166-75.

20. Ko SY, Kim KW. Nutrition label use, self-efficacy, snacking and eating behavior of middle school students in Kyunggi area. Korean J Community Nutr 2010;15:513-24.

21. Guthrie JF, Fox JJ, Cleveland LE, Welsh S. Who uses nutrition labeling, and what effects does label use have on diet quality? J Nutr Educ 1995;27:163-72.

22. Strazzullo P, D’Elia L, Kandala NB, Cappuccio FP. Salt intake, stroke, and cardiovascular disease: meta-analysis of prospective studies. BMJ 2009;339:b4567.

23. He FJ, MacGregor GA. Reducing population salt intake worldwide: from evidence to implementation. Prog Cardiovasc Dis 2010;52:363-82.

24. He FJ, Jenner KH, Macgregor GA. WASH-world action on salt and health. Kidney Int 2010;78:745-53.

25. Zhu K, Devine A, Dick IM, Wilson SG, Prince RL. Effects of calcium and vitamin D supplementation on hip bone mineral 
density and calcium-related analytes in elderly ambulatory Australian women: a five-year randomized controlled trial. J Clin Endocrinol Metab 2008;93:743-9.

26. Bischoff-Ferrari HA, Rees JR, Grau MV, Barry E, Gui J, Baron JA. Effect of calcium supplementation on fracture risk: a double-blind randomized controlled trial. Am J Clin Nutr 2008;87:1945-51.

27. Villegas R, Gao YT, Dai Q, Yang G, Cai H, Li H, et al. Dietary calcium and magnesium intakes and the risk of type 2 diabetes: the Shanghai Women's Health Study. Am J Clin
Nutr 2009;89:1059-67.

28. Wu K, Willett WC, Fuchs CS, Colditz GA, Giovannucci EL. Calcium intake and risk of colon cancer in women and men.J Natl Cancer Inst 2002;94:437-46.

29. Beaton GH, Milner J, McGuire V, Feather TE, Little JA. Source of variance in 24-hour dietary recall data: implications for nutrition study design and interpretation. Carbohydrate sources, vitamins, and minerals. Am J Clin Nutr 1983;37:98695. 